\title{
Influence of Moisture Content on the Mechanical Properties of Selected Wood-based Composites
}

\author{
Conrad M. Sala, ${ }^{\mathrm{a}}$ Eduardo Robles, ${ }^{\mathrm{b}}$ Aneta Gumowska, ${ }^{\mathrm{a}}$ Anita Wronka, ${ }^{\mathrm{a}}$ and \\ Grzegorz Kowaluk ${ }^{a, *}$ \\ Wood quality depends on many circumstances, as it is sensitive to \\ changing properties, depending on the environment. This work evaluates \\ the influence of moisture content of selected wood-based composites on \\ their basic mechanical properties, i.e., modulus of rupture and modulus of \\ elasticity. The selected panels were divided by application in construction \\ materials and furniture materials, which demand specific conditions during \\ service-life. The increase of moisture content in different types of wood- \\ based panels resulted in a slight reduction of the modulus of rupture and \\ the modulus of elasticity. Boards for use in dry conditions, mainly in the \\ furniture industry, were more sensitive to lowering their modulus of \\ elasticity with higher board moisture content compared with those \\ designed for humid conditions, mainly from the building industry.
}

Keywords: Wood-based panels; Moisture content; MOR; MOE

Contact information: a: Department of Technology and Entrepreneurship in Wood Industry, Warsaw University of Life Sciences - SGGW, Nowoursynowska St. 159, 02-776 Warsaw, Poland; b: Institute of Analytical and Physicochemical Sciences for the Environment and Materials (IPREM-UMR 5254), CNRS/Univ Pau \& Pays Adour/E2S UPPA, IUT of the Pays de l'Adour, 371 Rue du Ruisseau, 40004 Mont de Marsan, France; *Corresponding author: grzegorz_kowaluk@sggw.edu.pl

\section{INTRODUCTION}

Wood is widely processed, and it is a readily available good. It is a bio-based material; it degrades when exposed to atmospheric agents such as U.V. and rain, which cause swelling and shrinkage. Wood may also be exposed to the ravaging influence of different species of insects and fungi. After proper preparation, wood can be used for hundreds of years without significantly losing properties and structure. Moreover, it is one of the cheapest structural materials. It has a wide range of applications depending on its kind and the treatments applied, including construction, tools, furniture, decorative haberdashery, but also parts of engineering, machines, conveyances, and others.

Throughout the years, wood quality has different meanings to different people. Foresters consider tree size and morphology, while lumber manufacturers prefer straight logs with big diameter and clear of knots. For customers, wood quality is evaluated with other attributes; for example, the building industry is focused mainly on mechanical properties, stiffness, and dimensional stability (Johansson et al. 1994). However, wood as a natural material is sensitive for changing properties depending on many circumstances like wood type, age, and place of growth. These factors can influence, for example, radial growth and wood density (Guilley et al. 2004).

Another issue affecting the mechanical and physical properties of wood is the presence of knots, their amount, and size within the log. Knots decrease the strength of the wood by interrupting the direction of grains and changing their angle (As et al. 2006). 
There are other factors influencing wood properties such as humidity, density, shrinkage, etc., resulting in different thermal and acoustic properties (Krzysik 1975). One of the most important factors influencing the modulus of rupture (MOR) is wood moisture content (MC) as absolute humidity. Changes in moisture content that take place during the time from cutting the tree to the fiber saturation point (FSP; $c$. 30\%) are not so crucial because they do not have a significant impact on the final properties. Moisture content fluctuation changes the mechanical properties of wood-based composite panels (Halligan and Schniewind 1974; Wu and Suchsland 1997; Lin et al. 2002; Sombatsompop and Chaochanchaikul 2004; Janssen 2018).

Increasing the moisture content from dry wood to the FSP has an inversely proportional relationship with the mechanical properties of the material. Using wood with high moisture content causes loosening connections, warping, and deformations, and it may provoke various types of leaks in construction joinery. Using overdried wood is also harmful because of the potential deformation of such material. It is essential to adjust the equilibrium moisture content of the wood to match the ambient conditions of usage (Krzysik 1975). Another factor influencing wood MOR is density. There is a close relationship between density and compressive strength, as both are directly proportional (Chowdhury et al. 2012). A similar connection was noted by investigating other types of mechanical properties. Density depends on the wood type, but the positive relationships of density against key growth traits (diameter at breast height and height) and tree age are significant for pioneer trees (Chen et al. 2017). Also, wood-based panels are hygroscopic materials. Their moisture content is influenced by several factors, including density, the type and amount of adhesive, and relative air humidity (Tong 1986). As the influence of the density on moisture sorption is relatively small and proportional to the moisture level (Ganev et al. 2003), different wooden composites can be combined.

In Fig. 1 it is shown how the production of wood-based panels in Europe has increased continuously during the last twenty years. From 2000 to 2016, the most significant increase (over 80\%) was that of oriented strand boards (OSB) and the production of medium and high-density fiberboards (MDF/HDF), which nearly doubled. Plywood production increased by more than $30 \%$, while particleboard production experienced a $10 \%$ growth over the last 18 years. Nevertheless, particleboards continue to dominate the market. There was a slight increase (3\%) in imports of industrial coniferous round wood; this increase is lower as the use of wood has turned into the production of the wood-based panels.

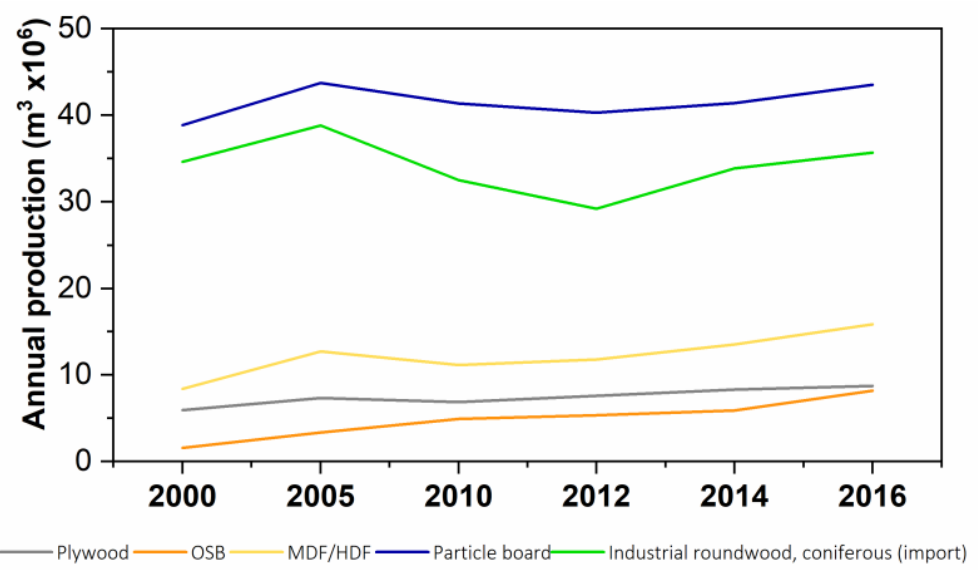

Fig. 1. European production of selected wood-based materials (source: own elaboration according to $\mathrm{FAO}$ ) 
The demand for wood-based panels is increasing. Part of this need is related to high investments in residential and commercial constructions across developing economies of the world, including China, India, Brazil, and Saudi Arabia (Grand View Research 2018). Consumption also is promoted by the increased availability of wood-based panels, tailoring them to fulfill different requirements represents a challenge for both the academic world and the industry.

For example, standard wooden composites may be produced in Europe to be used later in Asia, where climate conditions are very different. Some weather conditions, such as temperature and precipitation, show significant differences between central Europe and southwestern Asia (www.weatheronline.pl). Even though annual average conditions can be similar in some places, the particularity of some developing countries situated in the tropical region implies high precipitation rates in the middle of the year, while in the beginning and the end of the year, precipitation is on a similar level. According to EN standards regarding wood-based panels properties, the examination should be performed on conditioned samples to constant mass in a climate of $20 \pm 2{ }^{\circ} \mathrm{C}$ temperature and relative humidity $65 \pm 5 \%$ (EN 3101993 ).

There is a strong correlation between the production parameters of wood-based composites and their final properties. Increasing fiber moisture content from $6.5 \%$ to $10.5 \%$ during MDF production increases the MOR and modulus of elasticity (MOE) of boards by about $8 \%$ (Nicewicz and Monder 2014). Similarly, the internal bond (I.B.) can be $30 \%$ higher, and thickness swelling is decreased by approximately $22 \%$. By increasing material moisture content before producing wood-based panels, manufacturers may also increase the moisture content of manufactured boards (Thoemen et al. 2010; Nicewicz and Monder 2014). However, MDF boards with nominal density but higher moisture content are characterized by lower mechanical properties such as MOR, MOE, and I.B. (Ganev et al. 2005). Bekhta and Niemz (2009) investigated the influence of the relative humidity (and thus, material equilibrium moisture content - EMC) on the bending properties of fibrous composites, such as MDF panels of different density. They tested panels of average density 517,776 , and $931 \mathrm{~kg} / \mathrm{m}^{3}$. The samples had been conditioned under several humidity levels: $35,50,65,80$, and $95 \%$. They found that the EMC depends directly on the type of panel. Water is absorbed stronger when the panel density decreases. Also, there is a strong correlation between water absorption and bending strength. The reduction of bending strength and modulus of elasticity in fibreboards occurs due to the increase of moisture content. There has been no similar investigation of other wood-based composites commercially available. Even if the moisture-related mechanical properties concern industrially produced wood-based composites, these data are most often out-of-date. This situation is because in the last few years, one can observe changes in raw materials (wood, low molar ratio resins/binders, additives) and technological parameters (pressing time and temperature). Thus, it is necessary to provide results of high, practical, and current potential, and to promote discussion about the standard requirements of the strength of wood-based composites, especially applied in a rapidly developing frame, low energetic, or passive house constructions.

In addition to the mechanical properties of the panels changing with moisture content, surface properties can be dependent. The surface roughness of the panels rises when exposed to increasing air humidity in the range of 65 to $85 \%$. Additionally, the highest adhesion strength of the polyurethane coating occurs for the composite surface exposed to 65\% relative humidity (Ozdemir et al. 2009). Boards producers may offer panels used in dry and humid conditions, also considering different use classes of wood- 
based products (EN 335 2013). Composites may be adjusted for exterior exposure by using the proper glue, adjusting panel moisture content, or surface treatment (WIS 2/3-11 2013).

The mechanical parameters, including bending strength and modulus of elasticity, characterize the materials in light of their further application in changing humidity conditions. Factors including rainfall, fluctuations in relative humidity and temperature, sunlight, the ease of drying, fungal organisms, and insect attacks have a significant effect on the performance of wood-based panels exposure for exterior use. This work aimed to determine the influence of the moisture content of selected wood-based composites on their basic mechanical properties, such as MOR and MOE.

\section{EXPERIMENTAL}

\section{Sample Selection}

Seven different commercially used wood-based panels from the furniture and building industry, produced in Poland, were selected (Fig. 2). Four different composites designed for use under dry conditions were chosen from the furniture industry: highdensity fiberboard (HDF), medium density fiberboard (MDF), raw particleboard (rPB), and laminated particleboard (lPB). Three composites designed for humid conditions were chosen from the building industry: 3-layer plywood (3-ply), a P5 (EN 312 2010) grade multi-functional panel (MFP), and an oriented strand board (OSB). The wood raw material for the production of mentioned panels (excluding beech (Fagus sylvatica L.) plywood) in over 95\% was pine (Pinus sylvestris L.), the remaining are other softwood (mostly spruce Picea abies (L.) H. Karst) or hardwood species. The measured thicknesses and densities of each board are presented in Fig. 3, which shows a direct relationship between the density and thickness of the selected panels.

a)

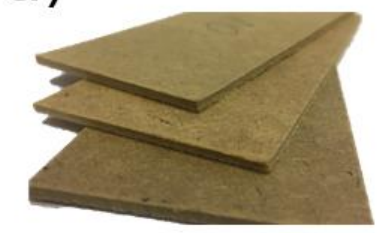

d)

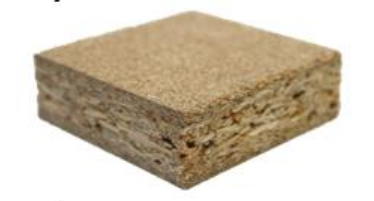

g)

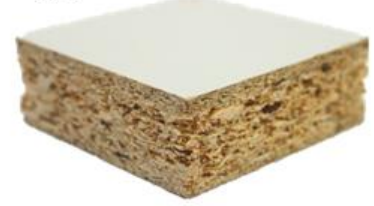

b)

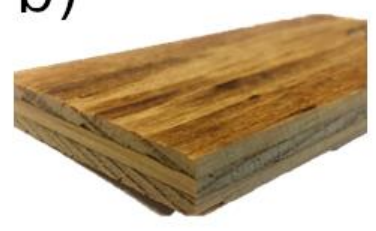

e)

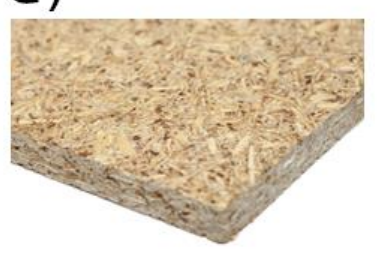

C)

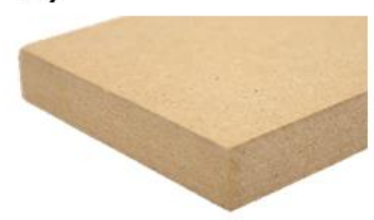

f)

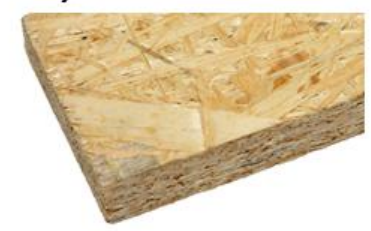

Fig. 2. The pictures of tested panels: a) HDF, b) 3-ply (plywood), c) MDF, d) rPB (raw particleboard), e) MDF, f) OSB, g) IPB (laminated particleboard) 


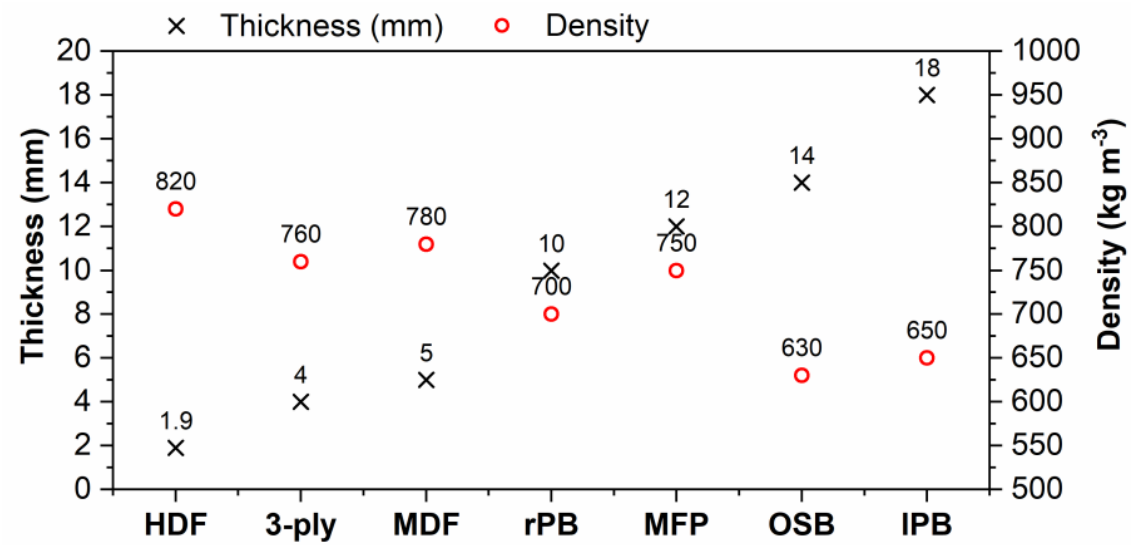

Fig. 3. Thickness and density of tested panels

\section{Sample Conditioning}

Twelve specimens for each board type and different air equilibrium moisturecontent were prepared according to EN 326-1 (1993). The specimens were dried at $70{ }^{\circ} \mathrm{C}$ until they reached a moisture content of 0\% (ASTM C1498-01 2001) to avoid any chemical or structural changes of the specimens caused by temperature and to obtain a constant weight. After drying, specimens were divided into four groups and were conditioned for 14 days at a constant temperature of $22 \pm 1{ }^{\circ} \mathrm{C}$ to reach constant mass stage according to ISO 12571 (2013). According to this standard, the constant mass stage was reached, when the change of mass between three consecutive weighings, each made $24 \mathrm{~h}$ apart, differ by less than $0.1 \%$ of the total mass. The first group of samples was kept with $0 \%$ of moisture content as a reference sample, while the rest of them were put into climate chambers according to the desiccator method described in ISO 12571 (2013). The specific air humidities were achieved through saline solutions, being magnesium chloride $\left(\mathrm{MgCl}_{2}\right)$ used for the second group (33\% relative humidity), cobalt II chloride $\left(\mathrm{CoCl}_{2}\right)$, for the third group (65\% R.H.) and potassium sulfate $\left(\mathrm{K}_{2} \mathrm{SO}_{4}\right)$ for the fourth group (97\% R.H.). The sample preparation and testing steps are presented in Table 1.

Table 1. The Steps of Sample Preparation and Testing

\begin{tabular}{|c|c|c|c|c|c|}
\hline Stage & Action & \multicolumn{4}{|c|}{ Parameters } \\
\hline 1. & Conditioning (kiln drying) & \multicolumn{4}{|c|}{$70^{\circ} \mathrm{C}$; all samples } \\
\hline 2. & Divide samples to groups & $1^{\text {st }}$ group & $2^{\text {nd }}$ group & $3^{\text {rd }}$ group & $4^{\text {th }}$ group \\
\hline \multirow[t]{2}{*}{3.} & \multirow[t]{2}{*}{ Conditioning to EMC } & $0 \%$ R.H. & $33 \%$ R.H. & $65 \%$ R.H. & 97\% R.H. \\
\hline & & \multicolumn{4}{|l|}{$22 \pm 1^{\circ} \mathrm{C}$} \\
\hline 4. & Mechanical testing & all sample & & & \\
\hline
\end{tabular}

\section{Mechanical Testing}

After sample conditioning, mechanical tests were done on an Instron 3369 universal testing machine (Norwood, MA, USA) with Instron Bluehill data acquisition software. The three-point bending test was performed according to EN 310 (1993). The MOE and MOR were calculated from 12 samples per each group, with samples of width $50 \pm 1 \mathrm{~mm}$ and length accordingly to the standard. After mechanical tests, moisture content was examined according to EN 322 (1993) on samples of $50 \times 50( \pm 1) \mathrm{mm}^{2}$.

One-way analysis of variance (ANOVA) at the $\mathrm{P}<0.05$ significance level was conducted on the average values of investigated features. Statistical analyses were performed using IBM SPSS Statistics 22 software (Armonk, NY, USA). 


\section{RESULTS AND DISCUSSION}

In the present study, there was a general trend in the moisture content of the boards. At higher climate humidity, the final air equilibrium moisture content of the wood-based panel was higher. However, differences in moisture content depended on the type of board. The moisture content of the different panels at varying air humidity is shown in Fig. 4. Samples conditioned under climate with magnesium chloride (33\% air humidity) were characterized by moisture content in the range of $2.4 \%$ to $4.9 \%$. The lowest value was for the thinnest product $(1.9 \mathrm{~mm})$, which was HDF, corresponding to the panel with the highest density $\left(820 \mathrm{~kg} / \mathrm{m}^{3}\right)$, so this could have slightly influenced this result, while the highest moisture content was for MFP boards. Samples kept in a climate with cobalt II chloride (65\% humidity) were characterized by moisture content in the range of $3.9 \%$ for HDF to $6.3 \%$ for the 3- ply. Because 3-ply is made of the largest wooden materials (natural beech veneer), the influence of the specific surface of the particles interacting with water is more substantial. Additionally, this material is dedicated to be used in dry conditions only, and the wood species might have influenced the final result. The moisture content of raw particleboard, MFP, and OSB was approximately 5\%. The lowest moisture content of samples from the group kept in a climate with potassium sulfate ( $97 \%$ humidity) was observed in MFP, while the highest was 3-ply. The moisture content of laminated particleboard (14.7\%) compared with rPB (16.7\%) was $12 \%$ lower, which was influenced by the finishing of the surfaces. A similar difference (13\%) was noticed between MDF (13.9\%) and HDF (15.9\%). This might be caused by lower MDF density $\left(780 \mathrm{~kg} / \mathrm{m}^{3}\right)$ compared with HDF $\left(820 \mathrm{~kg} / \mathrm{m}^{3}\right)$ and its lower water absorption potential. The moisture content values of tested materials under different ambient air parameters were statistically different when comparing the same materials under different air humidity.

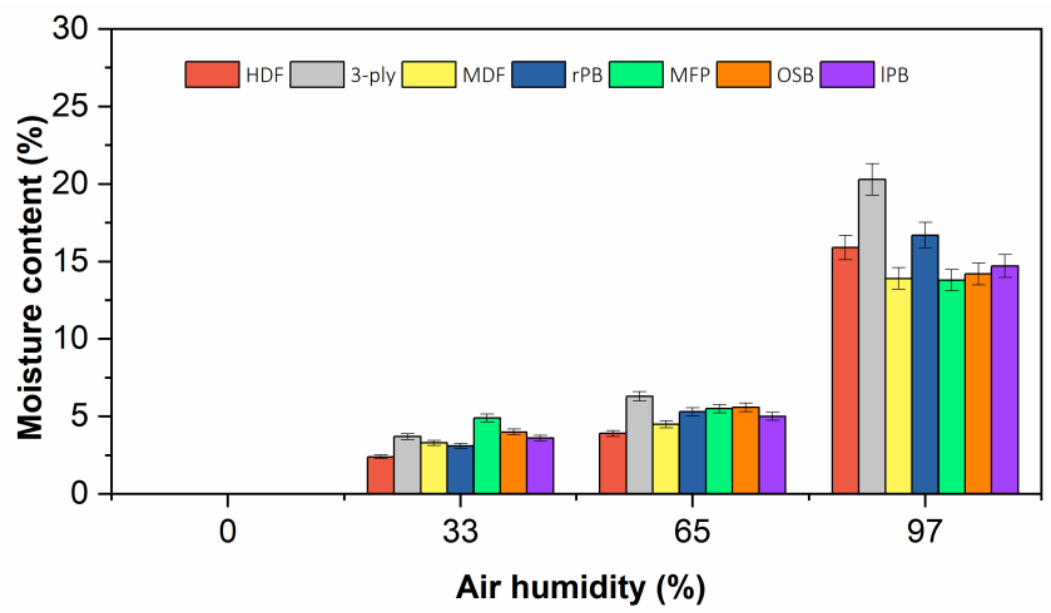

Fig. 4. The measured moisture content of tested panels related to the air humidity

The impact of moisture content on MOR is shown in Table 2. The MOR of tested panels slightly decreased or stayed at the same level when increasing the moisture content of samples from the $2^{\text {nd }}$ and $3^{\text {rd }}$ groups. In contrast, for the samples from the fourth group, the drop compared to reference samples was significant. A statistical analysis of MOR values confirmed that in the case of the $1^{\text {st }}, 2^{\text {nd }}$, and $3^{\text {rd }}$ groups, the only statistically significant difference was found in the case of MOR for 3-ply plywood of the $1^{\text {st }}$ and $3^{\text {rd }}$ group (Table 3). The remaining MOR values for this group did not represent statistically 
significant differences. When compared with the $3^{\text {rd }}$ and $4^{\text {th }}$ groups, a statistically significant drop of MOR was found for all the tested panels, excluding OSB. The MOR for panels conditioned with magnesium chloride and cobalt II chloride (excluding HDF and 3ply samples) was comparable to reference samples. For panels conditioned with potassium sulfate, a decrease of about $70 \%$ for HDF, plywood, and MDF was perceptible. In comparison, for the rest of the samples from that group, it ranged from $20 \%$ to over $35 \%$. The significant drop of the MOR values over $65 \%$ air humidity is in line with the results achieved by Bekhta and Niemz (2009) for MDF of different density. They found that the reduction of MOR of these panels over 65\% R.H. is more intensive for fibrous panels of higher density. The same conclusion can be given when comparing the MOR results of HDF and MDF, especially under 65 and 97\% R.H.

Table 2. Results of MOR Mean Values for Different Air Humidity

\begin{tabular}{|c|c|c|c|c|c|c|c|}
\hline $\begin{array}{c}\text { Air } \\
\text { humidity }\end{array}$ & HDF & 3-ply & MDF & rPB & MFP & OSB & IPB \\
\hline$(\%)$ & \multicolumn{7}{|c|}{$\left[\mathrm{N} \mathrm{mm}^{-2}\right]$} \\
\hline \multirow{2}{*}{0} & 59.5 & 138.6 & 44.3 & 9.5 & 22.9 & 21.8 & 14.0 \\
\cline { 2 - 8 } & $(5.9)$ & $(13.6)$ & $(1.5)$ & $(2.4)$ & $(1.7)$ & $(3.9)$ & $(1.0)$ \\
\hline \multirow{2}{*}{33} & 60.3 & 122.1 & 44.3 & 12.3 & 26.9 & 21.3 & 15.1 \\
\cline { 2 - 8 } & $(3.1)$ & $(8.1)$ & $(3.4)$ & $(1.5)$ & $(2.7)$ & $(3.6)$ & $(0.7)$ \\
\hline \multirow{2}{*}{65} & 55.2 & 101.7 & 43.0 & 11.5 & 24.5 & 19.7 & 15.1 \\
\cline { 2 - 8 } & $(6.2)$ & $(8.8)$ & $(2.2)$ & $(1.5)$ & $(2.2)$ & $(4.0)$ & $(1.0)$ \\
\hline \multirow{2}{*}{97} & 13.0 & 52.7 & 13.0 & 7.6 & 18.2 & 13.9 & 9.3 \\
\cline { 2 - 8 } & $(1.7)$ & $(4.1)$ & $(1.4)$ & $(0.8)$ & $(1.4)$ & $(2.4)$ & $(1.2)$ \\
\hline
\end{tabular}

Standard deviation values in parentheses

Table 3. Results of MOR Mean Values Statistical Analysis

\begin{tabular}{|c|c|c|c|}
\hline \multicolumn{4}{|c|}{ HDF } \\
\hline & 33 & 65 & 97 \\
\hline 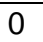 & 0.0898 & 0.4384 & 0.0001 \\
\hline 33 & & 0.0740 & 0.0329 \\
\hline 65 & & & $\overline{0.0001}$ \\
\hline
\end{tabular}

3-ply

\begin{tabular}{|c|c|c|c|}
\hline & 33 & 65 & 97 \\
\hline 0 & 0.0578 & $\underline{0.0211}$ & $\underline{0.0002}$ \\
\hline 33 & & $\underline{0.0407}$ & $\underline{0.0162}$ \\
\hline 65 & & & $\underline{0.0085}$ \\
\hline
\end{tabular}

MFP

\begin{tabular}{|c|c|c|c|}
\hline & 33 & 65 & 97 \\
\hline 0 & 0.0741 & 0.0774 & 0.0004 \\
\hline 33 & & 0.4903 & 0.4903 \\
\hline 65 & & & 0.0182 \\
\hline
\end{tabular}

\begin{tabular}{llll}
\hline & 33 & 65 & 97 \\
\hline 0 & 0.0524 & 0.2120 & $\underline{\underline{\mathbf{0 . 0 3 3 8}}}$ \\
33 & & 0.2494 & $\underline{\underline{\mathbf{0 . 0 2 0 2}}}$ \\
\hline 65 & & & $\underline{\underline{\mathbf{0 . 0 3 8 5}}}$ \\
\hline
\end{tabular}

\begin{tabular}{llll}
\multicolumn{2}{l}{ OSB } \\
\hline & 33 & 65 & 97 \\
\hline 0 & 0.4126 & 0.4673 & 0.0640 \\
33 & & 0.3810 & 0.0549 \\
\hline 65 & & & 0.0548 \\
\hline
\end{tabular}

\begin{tabular}{llll}
\multicolumn{2}{l}{ IPB } \\
\hline & 33 & 65 & 97 \\
\hline 0 & 0.1908 & 0.4485 & $\underline{\mathbf{0 . 0 2 6 3}}$ \\
33 & & 0.1582 & $\underline{\mathbf{0 . 0 2 8 1}}$ \\
\hline 65 & & & $\underline{\underline{\mathbf{0 . 0 3 0 7}}}$ \\
\hline
\end{tabular}

Highlighted data indicate statistically significant differences.

The highest decrease of MOR was found in 3-ply, which was likely caused by the higher moisture content of the panel compared with the other samples. Materials for the building industry have more resistance against bending stress after increasing the moisture content, while materials dedicated to the furniture industry suffer a more prominent decrease. However, from fourth group samples, only MFP met the requirements of bending 
strength according to standard EN 312 (2010). In contrast, all samples from other groups met minimal requirements for bending strength. The lowest decrease in strength was for particleboards; however, it was a drop of over $20 \%$ from average about $9.5 \mathrm{~N} / \mathrm{mm}^{2}$ for reference P.B. to an average of about $7.6 \mathrm{~N} / \mathrm{mm}^{2}$ for samples from the $4^{\text {th }}$ group. Moreover, the general trend of decreasing MOR with thickness increase was noticed in samples 1 to 3 , besides 3-ply and rPB. The required minimal MOR for the tested panels is shown in Table 4, according to the specified standards.

There is a linear relationship between MC and the reduction of the MOE of selected wood-based panels (Wu and Suchsland 1997). As shown in Table 5, there were significant differences in MOE between samples kept in a climate with $65 \%$ and $97 \%$ humidity (decrease from $29 \%$ for 3-layer plywood up to $75 \%$ for HDF), as well as between reference samples and those kept in a climate with $65 \%$ humidity. A similar tendency of intensive reduction of MOE over 65\% R.H. has been found by Bekhta and Niemz (2009). When the ambient air humidity was raised from 65 to $95 \%$, the MOE values dropped for about 66 and $84 \%$ for MDF and HDF, respectively. This is similar to the phenomena found in Table 4, where the MOE reduction for HDF was more significant than for MDF when R.H. was raised from 65 to $97 \%$.

Table 4. Results of MOE Mean Values for Different Air Humidity

\begin{tabular}{|c|c|c|c|c|c|c|c|}
\hline $\begin{array}{c}\text { Air } \\
\text { humidity }\end{array}$ & HDF & 3-ply & MDF & rPB & MFP & OSB & IPB \\
\hline$(\%)$ & \multicolumn{7}{|c|}{$\left[\mathrm{N} \mathrm{mm}^{-2}\right]$} \\
\hline \multirow{2}{*}{0} & 5678 & 12718 & 3338 & 2257 & 4142 & 4338 & 2378 \\
\cline { 2 - 8 } & $(298)$ & $(805)$ & $(755)$ & $(816)$ & $(367)$ & $(563)$ & $(715)$ \\
\hline \multirow{2}{*}{33} & 5982 & 12821 & 3761 & 3113 & 4931 & 4599 & 3018 \\
\cline { 2 - 8 } & $(557)$ & $(582)$ & $(235)$ & $(347)$ & $(331)$ & $(544)$ & $(118)$ \\
\hline \multirow{2}{*}{65} & 3679 & 11352 & 3087 & 2490 & 3582 & 3815 & 2528 \\
\cline { 2 - 8 } & $(768)$ & $(531)$ & $(287)$ & $(411)$ & $(249)$ & $(331)$ & $(90)$ \\
\hline \multirow{2}{*}{97} & 949 & 8095 & 1223 & 1161 & 1728 & 2416 & 1197 \\
\cline { 2 - 8 } & $(210)$ & $(483)$ & $(190)$ & $(132)$ & $(208)$ & $(267)$ & $(165)$ \\
\hline
\end{tabular}

Standard deviation values in parentheses

Table 5. Results of MOE Mean Values Statistical Analysis

\begin{tabular}{|c|c|c|c|}
\hline \multicolumn{4}{|c|}{ HDF } \\
\hline & 33 & 65 & 97 \\
\hline 0 & 0.0541 & 0.0019 & 0.0084 \\
\hline 33 & & 0.0151 & 0.0010 \\
\hline 65 & & & 0.0001 \\
\hline
\end{tabular}
3-ply

\begin{tabular}{llll}
\hline \multicolumn{2}{c}{33} & 65 & 97 \\
\hline 0 & 0.1493 & $\underline{\underline{0.0418}}$ & $\underline{\underline{0.0225}}$ \\
33 & & $\underline{\mathbf{0 . 0 3 8 2}}$ & $\underline{\underline{\mathbf{0 . 0 2 7 3}}}$ \\
65 & & & $\underline{\underline{\mathbf{0 . 0 3 8 0}}}$ \\
\hline
\end{tabular}

MFP

\begin{tabular}{llll}
\multicolumn{2}{l}{ rPB } & & \\
\hline & 33 & 65 & 97 \\
\hline 0 & 0.0604 & 0.0745 & $\underline{\mathbf{0 . 0 0 0 0}}$ \\
33 & & $\underline{\mathbf{0 . 0 2 9 0}}$ & $\underline{\underline{\mathbf{0 . 0 0 1 7}}}$ \\
65 & & & $\underline{\mathbf{0 . 0 0 0 4}}$ \\
\hline
\end{tabular}

\begin{tabular}{llll}
\hline & 33 & 65 & 97 \\
\hline 0 & $\underline{0.0369}$ & $\underline{\underline{0.0408}}$ & $\underline{\underline{0.0267}}$ \\
33 & & $\underline{\mathbf{0 . 0 1 8 1}}$ & $\underline{\underline{\mathbf{0 . 0 3 0 2}}}$ \\
65 & & & $\underline{\mathbf{0 . 0 2 8 1}}$ \\
\hline
\end{tabular}

\begin{tabular}{llll}
\multicolumn{2}{l}{ OSB } \\
\hline & 33 & 65 & 97 \\
\hline 0 & 0.4571 & 0.0563 & $\underline{\mathbf{0 . 0 1 0 2}}$ \\
33 & & 0.0570 & $\underline{\underline{\mathbf{0 . 0 1 3 1}}}$ \\
65 & & & $\underline{\mathbf{0 . 0 2 4 4}}$ \\
\hline
\end{tabular}

\begin{tabular}{llll}
\multicolumn{2}{l}{ IPB } & & \\
\hline & 33 & 65 & 97 \\
\hline 0 & 0.0556 & 0.0705 & $\underline{\mathbf{0 . 0 2 9 1}}$ \\
33 & & $\underline{\mathbf{0 . 0 3 1 9}}$ & $\underline{\underline{\mathbf{0 . 0 1 4 2}}}$ \\
65 & & & $\underline{\mathbf{0 . 0 2 7 6}}$ \\
\hline
\end{tabular}

Highlighted data indicate statistically significant differences. 
The highest results of MOE of each board were noticed from the second group with moisture content in the range of $2.4 \%$ to $4.9 \%$. The lower and higher moisture content of boards influenced their sample deflection and loss in stiffness during testing. However, samples conditioned under $97 \%$ humidity reached the highest moisture content $(13.8 \%$ to $16.7 \%$ ), except the 3-ply plywood, and the tested panels did not meet the MOR requirements, which could be caused by adhesive used for that plywood. The remaining tested samples reached the MOE minimal requirements (Table 4 and Table 6). There were no statistically significant differences between MOE values for the $1^{\text {st }}$ and $2^{\text {nd }}$ groups (Table 5). When comparing the $2^{\text {nd }}$ and $3^{\text {rd }}$ groups, statistical disparities were found for all samples, excluding OSB. In the $3^{\text {rd }}$ and $4^{\text {th }}$ groups, a statistically significant decrease in MOE was found for all tested panels.

Table 6. MOR and MOE Requirements for the Selected Panels

\begin{tabular}{|c|c|c|c|c|c|c|c|}
\hline & HDF & 3-ply & MDF & rPB & MFP & OSB & IPB \\
\hline MOR (N/mm $\left.{ }^{2}\right)$ & 23 & $\mathrm{n} / \mathrm{a}^{*}$ & 30 & 11 & 18 & 20 & 11 \\
\hline MOE $\left(\mathrm{N} / \mathrm{mm}^{2}\right)$ & $\mathrm{n} / \mathrm{a}^{* *}$ & $\mathrm{n} / \mathrm{a}^{*}$ & 2700 & 1800 & 2550 & 3500 & 1600 \\
\hline
\end{tabular}

${ }^{*}$ due to a wide range of plywood strength classes in EN 636: standard, no specific strength data have been presented (EN 636 2015); ${ }^{* *}$ not applicable for $1.8-2.5 \mathrm{~mm}$ thickness range according to EN 622 standard (EN 622 2010)

\section{CONCLUSIONS}

1. The increase of moisture content in different types of wood-based panels resulted in a slight reduction of the MOR for boards with a moisture content of $6.0 \%$ compared with reference samples (from 3\% for the MDF up to $12 \%$ for 3-layer plywood), but also a significant reduction of MOR for boards with a moisture content of $16.0 \%$ to $78 \%$ for the HDF.

2. The beech plywood (3-ply) had the highest bending strength in all the tested air conditions (average MOR $104 \mathrm{~N} / \mathrm{mm}^{2}$ ). For the boards made for dry use, the highest bending strength was for HDF boards (average MOR $47 \mathrm{~N} / \mathrm{mm}^{2}$ ). The modulus of elasticity decreased (up to $83 \%$ for HDF) with panels moisture increasing to $16 \%$.

3. Boards for the furniture industry were more sensitive to lowering their MOE with higher board moisture content compared to those from the building industry dedicated to humid conditions (like OSB). This could be caused by the type of resin used for the production of these structural materials, which might have higher water resistance. Also, the resination of these materials can be higher compared to furniture panels.

\section{ACKNOWLEDGMENTS}

The authors acknowledge the Warsaw University of Life Sciences - SGGW and E2S UPPA Research Chair Partnership (BOIS) supported by the Excellence Initiative of the University of Pau and Pays de 1'Adour and the I-Site E2S. Selected portions of this work were done under the activity of Students Research Group of Furniture (Koło 
Naukowe Meblarstwa), Faculty of Wood Technology, Warsaw University of Life Sciences - SGGW, Poland. The authors would also thank Anna Nysk and Natalia Partyka (Faculty of Wood Technology, Warsaw University of Life Sciences - SGGW, Poland) for their help with sample preparation and testings.

\section{REFERENCES CITED}

As, N., Goker, Y., and Dundar, T. (2006). "Effect of knots on the physical and mechanical properties of Scots pine (Pinus sylvestris L.)," Wood Research 51(3), 51-58

ASTM C1498-01 (2001). "Standard test method for hygroscopic sorption isotherms of building materials," ASTM International, West Conshohocken, PA. DOI: 10.1520/C1498-01

Bekhta, P., and Niemz, P. (2009). "Effect of relative humidity on some physical and mechanical properties of different types of fibreboard," European Journal of Wood and Wood Products, 67(3), 339-342. DOI: 10.1007/s00107-009-0330-4

Chen, L., Xiang, W., Wu, H., Lei, P., Zhang, S., Ouyang, S., Deng, X., and Fang, X. (2017). "Tree growth traits and social status affect the wood density of pioneer species in secondary subtropical forest," Ecology and Evolution 7(14), 5366-5377. DOI: $10.1002 /$ ece 3.3110

Chowdhury, M. Q., Ishiguri, F., Hiraiwa, T., Matsumoto, K., Takashima, Y., Iizuka, K., Yokota, S., and Yoshizawa, N. (2012). "Variation in anatomical properties and correlations with wood density and compressive strength in Casuarina equisetifolia growing in Bangladesh," Australian Forestry 75(2), 95-99. DOI: 10.1080/00049158.2012.10676390

EN 310 (1993). "Wood-based panels. Determination of modulus of elasticity in bending and of bending strength," European Committee for Standardization, Brussels, Belgium.

EN 312 (2010). "Particleboards - Specifications," European Committee for Standardization, Brussels, Belgium.

EN 322 (1993). "Wood-based panels - Determination of moisture content," European Committee for Standardization, Brussels, Belgium.

EN 326-1 (1993). "Wood-based panels. Sampling, cutting and inspection. Sampling and cutting of test pieces and expression of test results," European Committee for Standardization, Brussels, Belgium.

EN 335 (2013). "Durability of wood and wood-based products - Use classes: definitions, application to solid wood and wood-based products," European Committee for Standardization, Brussels, Belgium.

EN 622 (2010). "Fibreboards. Specifications. Requirements for hardboards," European Committee for Standardization, Brussels, Belgium.

EN 636 (2015). "Plywood -Specification," European Committee for Standardization, Brussels, Belgium.

FAO. Forestry Production and Trade 2019. http://www.fao.org/faostat/en/\#data/FO (accessed April 1, 2020).

Ganev, S., Cloutiert, A., Beauregard, R., and Gendron, G. (2003). "Effect of panel moisture content and density on moisture movement in MDF," Wood and Fiber Science 35(1), 68-82.

Ganev, S., Gendron, G., Cloutier, A., and Beauregard, R. (2005). "Mechanical properties 
of MDF as function of density and moisture content," Wood and Fiber Science 37(2), 314-326.

Grand View Research. (2018). Wood Based Panel Market Analysis and Segment Forecasts to 2025, San Francisco, CA.

Guilley, E., Hervé, J. C., and Nepveu, G. (2004). "The influence of site quality, silviculture and region on wood density mixed model in Quercus petraea Liebl.," Forest Ecology and Management 189(1-3), 111-121. DOI: 10.1016/j.foreco.2003.07.033

Halligan, A. F., and Schniewind, A. P. (1974). "Prediction of particleboard mechanical properties at various moisture contents," Wood Science and Technology 8(1), 68-78. DOI: $10.1007 / \mathrm{BF} 00350644$

ISO 12571 (2013). "Hygrothermal performance of building materials and products Determination of hygroscopic sorption properties," International Organization for Standardization, Geneva, Switzerland.

Janssen, H. (2018). "A discussion of 'Characterization of hygrothermal properties of wood-based products - Impact of moisture content and temperature," Construction and Building Materials 185, 39-43. DOI: 10.1016/J.CONBUILDMAT.2018.07.018

Johansson, G., Kliger, R., and Perstorper, M. (1994). "Quality of structural timberproduct specification system required by end-users," Holz als Roh-und Werkstoff, 52(1), 42-48. DOI: 10.1007/BF02615017

Krzysik, F. (1975). "Nauka o drewnie," Państwowe Wydawnictwo Naukowe, Warsaw.

Lin, Q., Zhou, X., and Dai, G. (2002). "Effect of hydrothermal environment on moisture absorption and mechanical properties of wood flour-filled polypropylene composites," Journal of Applied Polymer Science 85(14), 2824-2832. DOI: 10.1002/app.10844

Nicewicz, D., and Monder, S. (2014). "The influence of moisture of fiber mats on the properties of MDF boards," Annals of Warsaw University of Life Sciences - SGGW Forestry and Wood Technology 88, 174-177.

Ozdemir, T., Hiziroglu, S., and Malkocoglu, A. (2009). "Influence of relative humidity on surface quality and adhesion strength of coated medium density fiberboard (MDF) panels," Materials \& Design 30(7), 2543-2546. DOI: 10.1016/J.MATDES.2008.09.036

Sombatsompop, N., and Chaochanchaikul, K. (2004). "Effect of moisture content on mechanical properties, thermal and structural stability and extrudate texture of poly(vinyl chloride)/wood sawdust composites," Polymer Int. DOI: 10.1002/pi.1535

Thoemen, H., Irle, M., and Sernek, M. (2010). Wood-Based Panels An Introduction for Specialists, Brunel University Press.

Tong, L. (1986). Moisture Transport in Wood and Wood-based Panels-A Literature Survey (Report), RISE, S.P. - Sveriges Tekniska Forskningsinstitut, Stockholm.

WIS 2/3-11. (2013). "Specification and use of wood-based panels in exterior situations," Wood Information Sheet, High Wycombe, U.K.

Wu, Q., and Suchsland, O. (1997). "Effect of moisture on the flexural properties of commercial oriented strandboards," Wood and Fiber Science 29(1), 47-57.

Article submitted: April 4, 2020; Peer review completed: May 16, 2020; Revised version received and accepted: May 23, 2020; Published: May 29, 2020.

DOI: $10.15376 /$ biores. 15.3.5503-5513 